\title{
Latent transparency and trust in government: Unexpected findings from two survey experiments
}

\author{
Stephan G. Grimmelikhuijsen ${ }^{\mathrm{a}}$, Suzanne J. Piotrowski ${ }^{\mathrm{b}, *}$, Gregg G. Van Ryzin ${ }^{\mathrm{b}}$ \\ ${ }^{a}$ Utrecht University School of Governance, Bijlhouwerstraat 6, 3511, ZC, Utrecht, the Netherlands \\ ${ }^{\mathrm{b}}$ School of Public Affairs and Administration, Rutgers University Newark, 111 Washington Street, Newark, NJ 07102, USA
}

\section{A R T I C L E I N F O}

\section{Keywords:}

Openness

Freedom of information

Trust

Federal government

Randomized experiment

\begin{abstract}
A B S T R A C T
Transparency is popularly believed to enhance the public's trust in government, yet experimental studies have found mixed results. One explanation is that public trust may respond more positively to a kind of "latent transparency" in which citizens highly value the mere potential for open access to government information, even if they may have more negative reactions when presented with the particular content of actual government information, documents, or data. To test this hypothesis, we designed two survey experiments in which samples of US adults were primed with general information about the Freedom of Information Act (FOIA) or the existence of open government data.

Compared to controls, we find that awareness of FOIA rights and requirements (latent transparency) tended to be unrelated, or even slightly negatively related, to trust of government agencies, contrary to our expectations. Our findings, combined with prior evidence, suggest that-even in the case of latent transparency-the popular belief in transparency's positive effects on citizen trust needs a more critical examination. Implications for the theory and practice of transparency are discussed.
\end{abstract}

\section{Introduction}

Countries and subnational governments around the world have passed numerous transparency laws over the last few decades. In 2011, this global reform movement solidified into a new organization-the Open Government Partnership (Piotrowski, 2016), which was founded with the help of former US President Barack Obama as part of his larger efforts to promote transparency and openness in government (McDermott, 2010). The transparency initiatives of the Obama Administration met resistance from existing policy measures limiting transparency and arguments concerning the pitfalls of transparency (Coglianese, 2009), and it remains an open question whether rising populism, nationalism, and global instability more generally mark a point of inflection in the transparency movement (see Ingrams, 2018; Relly \& Sabharwal, 2009). Nonetheless, transparency remains deeply rooted in historical traditions of liberal democracy (Meijer, 2015; Pasquier \& Villeneuve, 2007) and thus continues to be an important concern for many scholars, policy makers, and importantly, the public.

One of the enduring arguments for, and assumptions about, transparency centers on its effects on the public's trust in government policies and institutions. Media, politicians, citizens and pressure groups treat more government transparency as a solution that will near- automatically lead to more trust in government (). The basic assumption is that if government is more transparent there will be an 'open culture' with less room for cover-ups, secrets and mistakes (e.g. Bertot, Jaeger, \& Grimes, 2010). Therefore a government that is more transparent, or at least seen as more transparent, might be more trusted by the public.

However, these positive assumptions concerning the effect of transparency on public trust have been met with criticism in the academic literature (e.g. Worthy, 2010; Bannister \& Connolly, 2011). Scholars of public policy and administration have begun using experimental methods to probe transparency's effects on citizens, with a focus on how various types of transparency impact trust and confidence in government. Curiously, the empirical results have often been mixed, with greater transparency sometimes associated with more trust, sometimes less trust, and sometimes with little or no effect on trust at all (Cucciniello, Porumbescu, \& Grimmelikhuijsen, 2017). Despite the sometimes negative response to being exposed to government information, most people have been found to have a clear preference for the general ideas of open access to public records (Cuillier, 2008; Cuillier \& Piotrowski, 2009) and transparency in government (Piotrowski \& Van Ryzin, 2007).

In this article, we explore the paradox of previous, conflicting

\footnotetext{
* Corresponding author.

E-mail addresses: S.G.Grimmelikhuijsen@uu.nl (S.G. Grimmelikhuijsen), spiotrow@rutgers.edu (S.J. Piotrowski), vanryzin@rutgers.edu (G.G. Van Ryzin).
} 
findings and propose the idea that public trust may be enhanced more consistently by what we term latent transparency, which we define as awareness of the right to access government information. We call this latent transparency, since it refers to the potential of being able to access government information, without necessarily intending to, or actually accessing, such information. We distinguish this from manifest transparency, which happens when citizens gain access to actual government documents, data, or information. The existing experimental literature examining the links between transparency and trust to date has focused on manifest transparency (Cucciniello et al., 2017; Grimmelikhuijsen, Weske, Bouwman, \& Tummers, 2017), which in practice is often a complex bundle of concrete information and conflicting indicators of government activities and accomplishments.

The effects of latent transparency on trust, however, have neither been distinguished theoretically nor investigated empirically. In our study, we probe this latent transparency proposition using a set of online survey experiments involving national samples of US adults in which we randomly induce basic awareness of the Freedom of Information Act (FOIA), the US law requiring transparency and openness in the federal government, and then examine its effect on trust in various federal agencies. FOI Acts have been enacted across the globe and have been found to effectively increase government transparency in several countries (e.g. Worthy, John, \& Vannoni, 2017; Spac, Voda and Zagrapan 2018; Grimmelikhuijsen, John, Meijer, \& Worthy, 2019). Despite the fact that the literature and political rhetoric widely assumes that transparency has positive effects on trust and legitimacy, we find that awareness of FOIA rights and requirements tends to be unrelated, or even negatively related, to trust of federal agencies. We discuss potential explanations for this counterintuitive and indeed unexpected finding, at least from the perspective of the transparency and open government movement.

In the sections that follow, we begin by defining transparency. We provide background information on freedom of (or access to) information as a key transparency policy and the related scholarship in this area, with a focus on findings from a growing number of experimental studies. This is followed by a presentation of our latent transparency proposition. We then present the design, methods, and findings of our two online survey experiments, which, as mentioned, run counter to our theoretical expectations. We conclude with a discussion and interpretation of these counterintuitive findings and their implications for transparency scholarship and public policy.

\section{Freedom of information, transparency, and trust}

Transparency constitutes part of the current open government reform agenda, which bundles prior reform initiatives and focuses on transparency, collaboration, and participation (McDermott, 2010). Transparency has been touted as a political and administrative fix for a variety of issues including corruption (Schnell, 2017), lack of policy understanding (Porumbescu et al2017), and decreasing trust in government (Worthy, 2010). However, empirical investigations have shown that the relationship between transparency and other variables such as trust and corruption are tenuous, however, and at times run counter to the prevailing political and reform rhetoric. For example, Bauhr and Grimes (2014) cross-national study found that "an increase in transparency in highly corrupt countries tends to breed resignation rather than indignation" (291). In other words, they did not find an increase in accountability with an increase in transparency. Conversely, in a cross-disciplinary, systematic review of the transparency literature, Cucciniello et al. (2017) found that the existing literature in general "suggests that greater transparency results in less corruption" (40).

In our conceptualization, we use Grimmelikhuijsen and Meijer's (2014) definition of transparency as "the availability of information about an actor that allows other actors to monitor the workings or performance of the first actor" (139). This broad definition leaves room for various distinctions. For instance, transparency can refer to information about decisions, policy or performance of an actor (Cucciniello et al., 2017), to decision processes or to decision explanations (de Fine Licht, Naurin, Esaiasson, \& Gilljam, 2014).

The existing literature has tested the effects of these and other important features of government transparency yet, in doing so, scholars have largely focused on what we call manifest transparency. Manifest transparency occurs when individuals have access to, or engage with, specific government documents, data, or information. Survey research has found positive correlations between manifest transparency and trust (Tolbert \& Mossberger, 2006; Im, Cho, Porumbescu, and Park 2014). However, in a systematic review of the literature on transparency, Cucciniello et al. (2017) found a pattern suggesting a potential methodological bias in favor of a positive relationship. Experiments and case studies have tended to produce negative or mixed findings, while research conducted using survey data have more often shown a positive relationship. Most likely, this is due to the vulnerability of cross-sectional surveys to issues such as common source bias (Favero \& Bullock, 2014) and endogeneity (James, Jilke, \& Van Ryzin, 2017).

Experiments aim to overcome these issues by randomly assigning groups of participants to various transparency conditions in order to probe their causal effects on trust. In the experimental designs to date, the focus again has been on manifest transparency such as information on government websites, performance reports, or newspaper articles (de Fine Licht, 2011). Moreover, experiments have used various substantive topics, such as environmental issues (Grimmelikhuijsen \& Meijer, 2014), health care (Porumbescu, Lindeman, Ceka, \& Cucciniello, 2017), and traffic safety (de Fine Licht, 2014). The findings of these experiments have been mixed, with effects conditional on the type of respondents and the substantive topic. For instance, Grimmelikhuijsen and Meijer (2014) used air pollution maps to probe transparency and found that they did have an effect on some citizens (particularly less knowledgeable and less trusting citizens) but not on others. de Fine Licht, Naurin, Esaiasson, \& Gilljam (2014) found that certain types of transparency can indeed increase trust, especially when they focus on the reasons behind a policy decision. Porumbescu and Grimmelikhuijsen (2017) found that disclosing elements of decisionmaking that highlight a fair process, such as neutrality and voice, enhances citizens' trust. These findings suggest that trust may be influenced less by information about manifest outcomes of government and more by transparency of official decision-making procedures. Indeed, the importance of perceptions of procedural justice to the formation of trust judgments has been well demonstrated in the context of policing and the courts (e.g. Tyler, 2006, 2013), as well as for trust of public administrators more generally (Van Ryzin, 2011).

Thus, although the body of research using experimental designs to examine the causal relationship between transparency and trust is growing, results remain mixed. Effects appear to be contingent on policy domain (de Fine Licht, 2014), prior attitudes (Grimmelikhuijsen \& Meijer, 2014), and even presentation format (Porumbescu et al., 2017). The generally mixed, and sometimes even negative, effects of manifest transparency on trust may be attributable to the fact that transparency in these studies is always about a substantive topic-some specific facts, documents, or information about government-that may provide a less than flattering view of government performance. In addition, the mixed effects of manifest transparency may be a reflection in part of processes of motivated reasoning (James \& Van Ryzin, 2016); that is, people may interpret information about government in ways that simply confirm and thus strengthen their prior beliefs (Taber and Lodge 2006).

Relatedly, even when only positive information is provided, citizens are known to have a generally negative view of government; thus, actually being exposed to more information (i.e., more transparency) about government may exacerbate this negativity bias (Marvel, 2015). In other words, it remains difficult to disentangle the principle of transparency from the bundle of information and other cues that typically make up manifest transparency treatments-the specific data, 
websites, reports, or other information about government-that are tested in much of this experimental work.

\section{Latent transparency}

One possible explanation for the conflicting findings from experimental and other studies on the effects of transparency may be that public trust depends more on the general awareness of transparency as a right-what we call latent transparency - rather than the direct experience of accessing actual government information, documents, or data (manifest transparency). Our concept of latent transparency in inspired by the work of Hibbing and Theiss-Morse (2002) on "stealth democracy," which argues that most citizens do not really desire direct democracy or regular participation in the political process. As these authors explain, "people want democratic procedures to exist but not to be visible on a routine basis" (2). And they elaborate a bit later on:

"The people want to be able to make democracy visible and accountable on those rare occasions when they are motivated to be involved. They want to know that the opportunity will be there for them even though they probably have no current intention of getting involved in government or even paying attention to it."

Indeed, Hibbing and Theiss-Morse's empirical evidence from survey data and other sources finds that most citizens view the actual debates and compromises involved in the democratic process to be unsatisfying, if not distasteful. "We believe a proper reading of the evidence," they write, "suggests that the consequences of popular participation are often neutral or negative" (5). Thus, citizens value democracy as a check on the abuse of power, even while not wanting to participate in the democratic process themselves.

In an analogous way, we hypothesize that citizens may value transparency as a principle or policy, even while not having much interest themselves in directly requesting or accessing public information, documents, or data. Indeed, when citizens are exposed to such government information-manifest transparency-they may even react negatively, as some of the prior research suggests. For example, pointing citizens to a comprehensive list of government grants and contracts may demonstrate transparency, but it also serves to remind people of the expense, complexity, and potential waste involved in government procurement. To take another example, one's response to public information about health policy (e.g., de Fine Licht, 2011) may well be strongly related to one's political values about how health care policy should be organized. Thus, being exposed to more extensive, real information may not (only) engender a response to increased transparency but may also interact with political values, preferences, and identities. Thus, in our experiments, in contrast to previous studies of the effects of manifest transparency, we do not vary the availability or extent of information about an agency or public service. Rather, we keep the amount of substantive information minimal and instead focus only on manipulating citizens' overall awareness of general transparency laws and policies.

The aim of our set of experiments, therefore, is to test whether latent transparency-exposing citizens only to the principle of transparency, independent of any government information, documents, or data-is positively related to citizen's trust in government. Our expectation is the following: Awareness of the right of transparency (latent transparency), which in the United States is represented in large part by the FOIA law, will have a direct, positive effect on trust of government and related attitudes. We test these expectations using two separate survey experiments.

\section{Study 1: priming awareness of the Freedom of Information Act}

In our first study, we aimed to manipulate basic awareness of the US FOIA in order to probe its causal effects on trust of government. We chose to prime awareness of FOIA since this is a legal backbone to undergird transparency in many countries across the globe (REF). Also
Random assignment $\rightarrow$

\begin{tabular}{|l|c|c|}
\hline $\begin{array}{c}\text { FOIA priming Qs } \\
\text { (treatment group) }\end{array}$ & $\begin{array}{c}\text { No prime } \\
\text { (control group) }\end{array}$ & $\begin{array}{c}\text { PRA priming Qs } \\
\text { (placebo group) }\end{array}$ \\
\hline \multicolumn{3}{|c|}{ Random assignment $\rightarrow$} \\
\hline NASA description & HHS description & IRS description \\
\hline
\end{tabular}

Fig. 1. Design of experiment, Study 1.

various studies have shown that FOIA requests have a significant positive effect on government transparency (e.g. Worthy et al., 2017; Spáč et al. 2018; Grimmelikhuijsen et al., 2019). We begin with the details of our experimental design, describe our online sample of US adult participants, and then present our findings.

\subsection{Experimental design}

Fig. 1 provides a summary of our first experimental design. At the start, participants were randomly assigned to either: 1) a FOIA prime, 2) a no-prime control condition, or 3) a placebo prime. The FOIA prime consisted of three questions that were adapted directly from the US government's main webpage for informing the public about FOIA (www.FOIA.gov) and read as follows:

The U.S. Freedom of Information Act (FOIA) is a law that gives you the right to access information from the federal government.

FOIA is often described as the law that keeps citizens in the know about their government.

- Have you ever heard about the Freedom of Information Act (FOIA)?

- Did you know that federal agencies are required to disclose any information requested under FOIA (unless exempt for reasons such as privacy, national security, or law enforcement)?

- Did you know that FOIA also requires agencies to proactively post online certain categories of information, including frequently requested records?

We chose to put this information into a set of yes/no/maybe questions, rather than just a written paragraph description of FOIA, in order to encourage our online participants to more carefully read and consider the basic information being presented about FOIA (see James \& Van Ryzin, 2016 for a similar approach). The randomly allocated respondents who received these FOIA questions constitute our treatment group, while those who did not get these priming questions represent our control group. We also set up a placebo group who were asked a set of similarly phrased yes/no/maybe questions (see Appendix A) about the Paperwork Reduction Act (PRA); this placebo group provides a robustness check on whether any observed effects of the FOIA priming questions were the result of FOIA transparency policies per se and not merely the result of having read and answered questions about any sort of rule or regulation with potential benefits to the public.

After being randomly assigned to the FOIA prime (treatment), the no-prime (control) condition, or the PRA prime (placebo), respondents were again randomly assigned to one of three federal agency descriptions:

National Aeronautics and Space Administration (NASA).

The National Aeronautics and Space Administration (NASA) is an independent agency of the executive branch of the United States federal government responsible for the civilian space program, as well as aeronautics and aerospace research. NASA has nearly 18,000 employees and an annual budget of $\$ 19$ billion.

Department of Health and Human Services (HHS).

The United States Department of Health and Human Services (HHS) is a 
cabinet-level department of the U.S. federal government with the goal of protecting the health of all Americans and providing essential human services. HHS has nearly 80,000 employees and annual budget of $\$ 1$ trillion.

Internal Revenue Service (IRS).

The Internal Revenue Service (IRS) is a bureau of the Department of the Treasury responsible for collecting taxes and administering the Internal Revenue Code, the federal statutory tax law of the United States. IRS has nearly 80,000 employees and annual budget of $\$ 12$ billion.

These three agencies were chosen so that our experiment would reflect a variety of types of agencies, and we selected them based in part on a Pew Research Center (2015) survey report on the public's favorability ratings of federal agencies (with NASA near the top, HHS in the middle, and the IRS near the bottom of the favorability distribution). The language in the descriptions was based on a compilation of agency website language and on Wikipedia entries for each agency and was edited by us so that the descriptions were similar in form, content, and word-count. With this setup, we aimed to test how the FOIA awareness prime influenced people's judgments of a variety of real federal agencies.

After reading their assigned agency description, respondents were asked to rate their trust of the federal agency shown to them using the following two items:

On a scale from 0 to 100, what percent of the time do you think citizens can trust this agency...

- To make decisions in a fair way

- To do what is best for the country

These two items come from the American National Election Studies pilot study of improved ways to measure trust in government (Gershtenson \& Plane, 2007). The sum of these items (alpha $=0.91$ ) constitutes our main dependent variable or outcome of interest.

In addition, we asked people the following two items on the perceived truthfulness and openness of government:

On a scale from 0 to 100, what percent of the time do you think citizens can trust this agency...

- To tell the truth

- To be open to the public

We added these items as a potentially more direct measure of the effect of our latent transparency manipulation. The sum of these items (alpha $=0.88$ ) thus provides a secondary dependent variable.

\subsection{Participants}

Our experiment was one of six short experiments included in an omnibus survey organized and funded by the School of Public Affairs and Administration, Rutgers University. The order of experiments in the omnibus survey was fully randomized. Participants were 1051 US adult members of a research panel managed by Qualtrics, an online survey software and research firm (www.qualtrics.com/online-sample/). Study invitations were distributed by Qualtrics and the online responses were gathered from October 23 to October 27, 2017. No demographic or geographic quotas were used, other than restricting the survey to adult residents of the United States. Respondents received a monetary incentive administered by Qualtrics for their participation. The omnibus survey, including our experiment, was approved by the Rutgers University Institutional Review Board prior to data collection.

As Table 1 shows, participants were disproportionately female $(83 \%)$ and under 40 in age (60\%), which reflects the general profile of the Qualtrics research panel. Our survey sample was fairly balanced, however, in terms of their political party identification and political ideology. Less than a third (28\%) had a four-year college degree or
Table 1

Characteristics of participants.

\begin{tabular}{lll}
\hline & Study 1 & Study 2 \\
\hline Sample size (n) & & \\
Sex (female) & $82.7 \%$ & $52.1 \%$ \\
Age (40 and higher) & $39.9 \%$ & $43.1 \%$ \\
Party identification: & $39.5 \%$ & $38.2 \%$ \\
$\quad$ Democrat & $24.2 \%$ & $32.0 \%$ \\
$\quad$ Independent & $30.5 \%$ & $29.8 \%$ \\
$\quad$ Republican & $05.8 \%$ & \\
$\quad$ Other & Mean $=3.01$ & Mean $=5.58$ \\
Political viewpoint (Exp 1: $1=$ very liberal, & SD $=2.65$ \\
$\quad 5=$ very conservative / Exp 2: $1=$ left & SD 0.98 & \\
$\quad 10=$ right) & $27.8 \%$ & $28.9 \%$ \\
Education (4 years of college or more) & $39.4 \%$ & $47.3 \%$ \\
Income (\$50,000 or higher) & & \\
\hline
\end{tabular}

higher, and about $60 \%$ had incomes of less than $\$ 50,000$. Thus the 'average' respondent is a female/woman under 40 with a modest income and without a college degree. In terms of their party identities and political views, which are most important for our experiment, the participants are more evenly distributed. We carried out balance tests and found no significant differences in these demographic and political characteristics between the experimental groups. ${ }^{1}$

\subsection{Findings}

To analyze the main effects, we carried out an ordinary least squares (OLS) regression analysis using three models, as shown in Table 2. Descriptive statistics with means and standard deviations across separate agencies can be found in Appendix B1. In the first model, we include only dummy variables for the FOIA prime (treatment group) and the PRA prime (placebo group), with the no-prime (control group) condition excluded as the reference category. In the second model, we add in control variables (see Table 1 for a summary of these variables). In the third model, we add in additional controls for the agency vignettes. As can be seen in Table 2, all three models consistently show a small yet significant negative effect of our main treatment (the FOIA prime) on trust in government. Interestingly, the coefficient for the placebo treatment (the PRA prime) is also negative, although not significant statistically. This indicates that priming people's awareness of the existence of the FOIA law reduces trust in government agencies. This is a surprising finding that runs counter to our proposition, that latent transparency would strengthen public trust. We will discuss some possible interpretations of this unexpected and counterintuitive finding in the discussion section.

Furthermore, we looked at the heterogeneous treatment effects across federal agencies. As explained earlier, we randomly assigned respondents to one of three different federal agencies (NASA, HSS, and IRS) to test the robustness of the FOIA priming effect across different types of agencies. Thus, we were able to carry out another regression analysis (Table 3) using the same regression models as before (see Table 2), but separately within each agency subsample. As Table 3 shows, the effect of the FOIA treatment appears most pronounced within the HHS subsample; in other words, participants who were exposed to the FOIA prime and then the description of HHS had significantly less trust in this agency. The effect of the FOIA awareness priming was weakest for the IRS, which as noted has been shown to be a relatively disfavored agency in the eyes of the public.

As mentioned earlier, in addition to our main dependent variable of trust from the ANES, we also included two of our own items that aimed

\footnotetext{
${ }^{1}$ Sex Chi2 $(2)=1.87, p=.393 /$ Age Chi2(12) $=7.91, p=792 /$ Education Chi2(16) $=16.03, p=.451) /$ income Chi2 $(2)=3.03, p=.220 /$ political viewpoint Chi2(8) $=4.81, p=.777 /$ party identification Chi2(14) $=15.68$, $p=.334)$
} 
Table 2

Main experimental results, Study 1. Significance levels are bolded when below 0.05

\begin{tabular}{|c|c|c|c|c|c|c|}
\hline Predictors & std. Beta & $\mathrm{p}$ & std. Beta & $\mathrm{p}$ & std. Beta & $\mathrm{p}$ \\
\hline (Intercept) & & 0.030 & & 0.006 & & 0.738 \\
\hline FOIA dummy $(1=$ FOIA $)$ & -0.096 & 0.008 & -0.084 & 0.020 & -0.089 & 0.010 \\
\hline PRA dummy $(1=$ PRA $)$ & -0.072 & 0.047 & -0.065 & 0.069 & -0.054 & 0.117 \\
\hline $\operatorname{Age}(1=40$ or older $)$ & & & 0.018 & 0.559 & 0.010 & 0.732 \\
\hline Income $(1=\$ 50 \mathrm{~K}$ or higher $)$ & & & 0.019 & 0.565 & 0.032 & 0.308 \\
\hline $\begin{array}{l}\text { Party identification } \\
\quad(1=\text { Dem })\end{array}$ & & & 0.115 & $<0.001$ & 0.114 & $<0.001$ \\
\hline Sex $(1=$ female $)$ & & & 0.032 & 0.297 & 0.039 & 0.190 \\
\hline $\begin{array}{l}\text { Education }(1=4 \text { yrs. college } \\
\quad \text { or more })\end{array}$ & & & 0.101 & 0.002 & 0.108 & $<0.001$ \\
\hline $\operatorname{Agency}(1=$ HHS $)$ & & & & & -0.182 & $<0.001$ \\
\hline $\operatorname{Agency}(1$ = IRS) & & & & & -0.328 & $<0.001$ \\
\hline Observations & 1050 & & 1035 & & 1035 & \\
\hline $\mathrm{R}^{2} /$ adjusted $\mathrm{R}^{2}$ & $0.007 / 0.005$ & & $0.033 / 0.026$ & & $0.114 / 0.106$ & \\
\hline
\end{tabular}

Table 3

Main effects on trust within each agency-subgroup, Study 1 . Significance levels are bolded when below 0.05

\begin{tabular}{|c|c|c|c|c|c|c|}
\hline \multirow[b]{2}{*}{ Predictors } & \multicolumn{2}{|l|}{ HHS } & \multicolumn{2}{|l|}{ IRS } & \multicolumn{2}{|l|}{ NASA } \\
\hline & std. Beta & $\mathrm{p}$ & std. Beta & $\mathrm{p}$ & std. Beta & $\mathrm{p}$ \\
\hline (Intercept) & & 0.684 & & 0.001 & & 0.147 \\
\hline FOIA prime & -0.173 & 0.009 & -0.041 & 0.492 & -0.089 & 0.148 \\
\hline PRA prime & -0.093 & 0.161 & -0.089 & 0.136 & 0.016 & 0.793 \\
\hline Age dummy ( $1=40$ or older $)$ & 0.015 & 0.788 & -0.054 & 0.299 & 0.089 & 0.098 \\
\hline Income dummy $(1=50 \mathrm{~K}$ or higher & 0.046 & 0.435 & -0.021 & 0.698 & 0.086 & 0.141 \\
\hline Party identification $(1=$ Dem $)$ & 0.149 & 0.009 & 0.120 & 0.020 & 0.105 & 0.052 \\
\hline $\operatorname{Sex}(1=F)$ & 0.027 & 0.631 & -0.009 & 0.855 & 0.120 & 0.026 \\
\hline $\begin{array}{l}\text { Education }(1=4 \text { yrs. college } \\
\quad \text { or more })\end{array}$ & 0.011 & 0.844 & 0.197 & $<0.001$ & 0.110 & 0.058 \\
\hline Observations & 311 & & 378 & & 346 & \\
\hline $\mathrm{R}^{2} /$ adjusted $\mathrm{R}^{2}$ & $0.049 / 0.027$ & & $0.058 / 0.040$ & & $0.061 / 0.041$ & \\
\hline
\end{tabular}

to capture perceived truthfulness and openness of government. The scale of these two items, which we call "perceived openness", was not significantly affected by the FOIA prime (see Appendix C). However, as with the results for trust, the FOIA treatment effect on perceived openness was slightly negative and thus in the opposite direction from our theoretical expectation.

\section{Study 2: refinement and extension}

Our second study builds on what we learned from the findings and limitations of our first experiment. We again aimed to manipulate basic awareness of FOIA in order to probe the causal effect of latent transparency on trust of government. But we made modifications to our FOIA prime, included a new Data.gov prime, and employed an alternative measure of trust of government agencies. Such digital open government websites have become a common government policy to increase transparency (e.g. Lourenço, 2015). This allowed us to probe the distinction between the proactive release of information (when governments disseminate information widely, frequently without a legal obligation to do so, on tools such as data portals) and the requestor model of release (when governments release information or documents only after a formal request for information). We also employed a larger and more representative online sample in this second experiment. We begin with the details of our second experimental design, describe our online sample of US adult participants, and then present the findings.

\subsection{Experimental design}

Fig. 2 provides a summary of our second experimental design, in which we again randomized participants to various primes (to activate awareness of latent transparency) and to a no-prime control condition.
Random assignment $\rightarrow$

\begin{tabular}{|c|c|c|c|}
\hline $\begin{array}{c}\text { Original FOIA } \\
\text { priming Qs } \\
\text { (From Study 1) }\end{array}$ & $\begin{array}{c}\text { Revised FOIA } \\
\text { priming Qs } \\
\text { (Requestor model) }\end{array}$ & $\begin{array}{c}\text { Data.gov priming Qs } \\
\text { (New treatment) }\end{array}$ & $\begin{array}{c}\text { No prime } \\
\text { (Control group) }\end{array}$ \\
\hline \\
$\begin{array}{c}\text { Trust of government agencies (0-100 scale) } \\
\text { (IRS, HHS, NASA, DHS, DoEd, CDC) }\end{array}$
\end{tabular}

Fig. 2. Design of experiment, Study 2.

In one arm of the experiment, participants receive the same FOIA prime as in Study 1. In an additional arm, we added a slightly modified version of our original FOIA prime that emphasized more the requestor model of FOIA, with the exact wording of the prime as follows:

The U.S. Freedom of Information Act (FOIA) is a law that gives you the right to access information from the federal government.

FOIA is often described as the law that keeps citizens in the know about their government.

- Have you ever heard about the Freedom of Information Act (FOIA)?

- Did you know you can use FOIA to request government information for many federal agencies through a website?

- Did you know that in many cases you can track the status of your FOIA request online?

In addition, we added a third arm to the experiment to probe the effects of an alternative open government initiative, Data.gov. The wording for this new prime, which was adapted from the Data.gov website, read as follows:

Data.gov is the federal government's open data website; it aims to make government more open and accountable.

Data.gov is managed and hosted by the U.S. General Services 


\section{Administration, Technology Transformation Service.}

- Have you ever heard about the website Data.gov?

- Did you know that Data.gov is a digital archive for government information, made available to the public?

- Did you know that over 250,000 datasets from the federal government on topics such as health, education, and the economy are available on Data.gov?

Again, we stuck with our strategy of putting this information into a set of yes/no/maybe questions, rather than just a written paragraph description of FOIA or Data.gov, in order to encourage our online participants to more carefully read and consider the primes. The randomly allocated respondents who received the original FOIA prime, the revised (requestor) FOIA prime, and the Data.gov (proactive release) prime constitute our treatment groups, while those who did not get any of these priming questions represent our control group.

After receiving the FOIA or Data.gov primes (treatments) or the noprime (control) condition, respondents were asked to rate their level of trust of six federal agencies using a similar trust question and scale as in Study 1. Specifically, we asked participants:

On a scale from 0 to 100, what percent of the time do you think the public can trust the following federal agencies to do what is right?

- The Internal Revenue Service (IRS)

- Department of Health and Human Services (HHS)

- National Aeronautics and Space Administration (NASA)

- Department of Homeland Security (DHS)

- The Department of Education (DoEd)

- The Centers for Disease Control and Prevention (CDC)

These agencies were chosen to include the three agencies from Study 1, plus an additional three agencies representing a range of functions. The order of presentation of the agencies was randomized to reduce order effects. For our main dependent variable, we constructed a summative scale of the six agency trust ratings.

The question wording ("what percent of the time...") is taken from the standard trust question in the American National Election Studies (ANES). The original wording of this item is "How much of the time do you think you can trust the government in Washington to do what is right?". We departed from the standard ANES question in two important ways. First, we replaced "Washington" with "federal agencies" because this better fits the subject of this study. Second, we replaced the traditional answer categories ("Just about always, most of the time, or only some of the time?") with a percentage. The answer categories have been criticized because it is too crude with only three answer categories and the categories are not counterbalanced. For instance, there is no "just about never" to counterbalance "just about always" (Gershtenson \& Plane, 2007).

\subsection{Participants}

Our second study was conducted as a stand-alone survey (not part of an omnibus survey). Participants were 1503 US adult members of a research panel managed by Qualtrics, with online responses gathered from May 8 to June 2, 2019. In contrast to Study 1, we set quotas by sex, age, race, and region of the United States to ensure a more representative sample. Respondents received a monetary incentive administered by Qualtrics for their participation, and the study was approved by the Rutgers University Institutional Review Board prior to data collection.

As Table 1 shows, $52 \%$ of our Study 2 sample was female, a more balanced gender distribution than in Study 1. Participants in Study 2 considered themselves political centrists (5.6 on a 10-point scale) and those with a 4-year college degree or higher constituted just under onethird of the sample (29\%). The Study 2 sample reported somewhat higher incomes, with $47 \%$ earning $\$ 50 \mathrm{~K}$ or higher compared with only $39 \%$ in Study 1 . We carried out balance tests and found no significant differences in the demographic and political characteristics between the experimental groups. ${ }^{2}$

\subsection{Findings}

Table 4 shows the main results of our second experiment. Descriptive statistics with means and standard deviations across separate agencies can be found in Appendix B2. The results indicate that there are no significant effects on trust of federal agencies for any of the primes. The original FOIA prime has a slightly negative association with trust, but the relationship is miniscule in magnitude and not at all significant statistically. The modified FOIA prime, which focused on the requestor model, also has no effect at all on trust of federal agencies. And the Data.gov prime is weakly negatively associated with trust, but again not significant statistically. As the right-hand columns in the Table 4 show, these null findings remain substantively the same when we add control variables to the model. Thus, these results clearly show that none of the latent transparency primes in Study 2 have any relationship to how respondents rate the trustworthiness of federal agencies.

In a follow-up analysis, as Table 5 shows, we repeated the main analysis but analyzed each agency separately to detect if there were any heterogeneous effects of our treatments on trust of particular federal agencies. Again, there are no significant effects on trust, although the FOIA prime (replication) has a marginally significant negative effect $(p<.10)$ on trust of both NASA and the Centers for Disease Control (CDC).

Overall, the results of our second experiment show that even with revisions and alternatives to our latent transparency primes, there still is no evidence of any positive effects on trust of federal agencies. To provide an overview, Fig. 3 compares the main results of both Study 1 and Study 2. It shows the small negative, yet significant, effects of the FOIA prime from Study 1, while at the same time highlighting the null effects for all treatment groups in Study 2. Overall this comparison of results indicates that latent transparency does not have a positive effect on trust in federal agencies. Indeed, the general pattern is one of slightly negative if not null effects of the various latent transparency primes on trust.

\section{Discussion and implications}

In two separate experimental studies, we attempted to test whether the mere awareness of transparency rights and requirements-what we call latent transparency-would have positive effects on trust of government agencies. But instead of becoming more trusting, as we anticipated, participants in Study 1 became less trusting of US federal government agencies after exposure to the FOIA prime intended to heighten awareness of latent transparency. In Study 2, we also found no evidence that participants became more trusting of government agencies after exposure to the latent transparency primes. If anything, the coefficients from Study 2 trended in a negative direction. Thus, overall, we found no indications of a positive relationship between latent transparency and trust in government-contrary to our theoretical expectations. These findings mirror some of what has been found with respect to manifest transparency and trust (e.g., Cucciniello et al., 2017; Grimmelikhuijsen et al., 2017) and add to the growing body of evidence that calls into question the existence of a strong, positive relationship between government transparency and trust. The next step in a research

\footnotetext{
${ }^{2}$ Sex Chi2(3) $=0.737, p=.864 / \operatorname{Age} \mathrm{F}(3,1505)=0.714, p=.543 /$ Education Chi2(18) $=15.775, p=.608) /$ income Chi2(3) $=0.337, p=.953 /$ political viewpoint Chi2(8) $=4.81, p=.777 /$ party identification Chi2(6) $=3.199, p=.783$ )
} 
Table 4

Main experimental results, Study 2. Significance levels are bolded when below 0.05

\begin{tabular}{|c|c|c|c|c|c|c|}
\hline Predictors & std. Beta & CI95 & $\mathrm{p}$ & std. Beta & CI95 & $\mathrm{p}$ \\
\hline (Intercept) & & & $<0.001$ & & & $<0.001$ \\
\hline FOIA prime (replication) & -0.01 & $-0.07-0.05$ & 0.732 & -0.00 & $-0.06-0.06$ & 1.000 \\
\hline FOIA prime (requestor) & -0.00 & $-0.06-0.06$ & 0.930 & -0.00 & $-0.06-0.07$ & 0.931 \\
\hline Data.gov prime & -0.03 & $-0.09-0.04$ & 0.391 & -0.02 & $-0.08-0.05$ & 0.602 \\
\hline Sex $(1=$ female $)$ & & & & -0.02 & $-0.07-0.04$ & 0.544 \\
\hline Age $(1=40$ or older $)$ & & & & 0.12 & $0.06-0.17$ & $<0.001$ \\
\hline Income $(1=\$ 50 \mathrm{~K}$ or higher $)$ & & & & 0.08 & $0.02-0.13$ & 0.007 \\
\hline Party identification $(1=$ Dem $)$ & & & & -0.00 & $-0.05-0.05$ & 0.984 \\
\hline $\begin{array}{l}\text { Education( } 1=4 \text { yrs. college } \\
\text { or more })\end{array}$ & & & & 0.02 & $-0.04-0.07$ & 0.523 \\
\hline Observations & 1506 & & & 1440 & & \\
\hline $\mathrm{R}^{2} /$ adjusted $\mathrm{R}^{2}$ & $0.001 /-0.001$ & & & $0.025 / 0.020$ & & \\
\hline
\end{tabular}

Table 5

Main effects on trust of each agency, Study 2.

\begin{tabular}{|c|c|c|c|c|c|c|c|c|c|c|c|c|}
\hline \multirow[b]{2}{*}{ Predictors } & \multicolumn{2}{|l|}{ IRS } & \multicolumn{2}{|l|}{ HHS } & \multicolumn{2}{|l|}{ NASA } & \multicolumn{2}{|l|}{ DHS } & \multicolumn{2}{|l|}{ DoEd } & \multicolumn{2}{|l|}{ CDC } \\
\hline & std. Beta & $\mathrm{p}$ & std. Beta & $\mathrm{p}$ & std. Beta & $\mathrm{p}$ & std. Beta & $\mathrm{p}$ & std. Beta & $\mathrm{p}$ & std. Beta & $\mathrm{p}$ \\
\hline (Intercept) & & $<0.001$ & & $<0.001$ & & $<0.001$ & & $<0.001$ & & $<0.00$ & & $<0.001$ \\
\hline FOIA prime (replication) & -0.01 & 0.761 & -0.02 & 0.443 & -0.05 & 0.098 & 0.03 & 0.358 & 0.05 & 0.132 & -0.05 & 0.096 \\
\hline FOIA prime (requestor) & -0.00 & 0.932 & -0.02 & 0.505 & -0.00 & 0.967 & -0.02 & 0.553 & 0.04 & 0.173 & -0.02 & 0.525 \\
\hline Data.gov prime & -0.03 & 0.395 & -0.04 & 0.250 & -0.04 & 0.239 & -0.01 & 0.829 & 0.02 & 0.465 & -0.02 & 0.555 \\
\hline Observations & \multicolumn{2}{|c|}{1501} & \multicolumn{2}{|c|}{1502} & \multicolumn{2}{|c|}{1501} & \multicolumn{2}{|c|}{1500} & \multicolumn{2}{|c|}{1498} & \multicolumn{2}{|c|}{1504} \\
\hline $\mathrm{R}^{2} /$ adjusted $\mathrm{R}^{2}$ & \multicolumn{2}{|c|}{$0.001 /-0.001$} & \multicolumn{2}{|c|}{$0.001 /-0.001$} & \multicolumn{2}{|c|}{$0.003 / 0.001$} & \multicolumn{2}{|c|}{$0.002 /-0.000$} & \multicolumn{2}{|c|}{$0.002 /-0.000$} & \multicolumn{2}{|c|}{$0.002 /-0.000$} \\
\hline
\end{tabular}

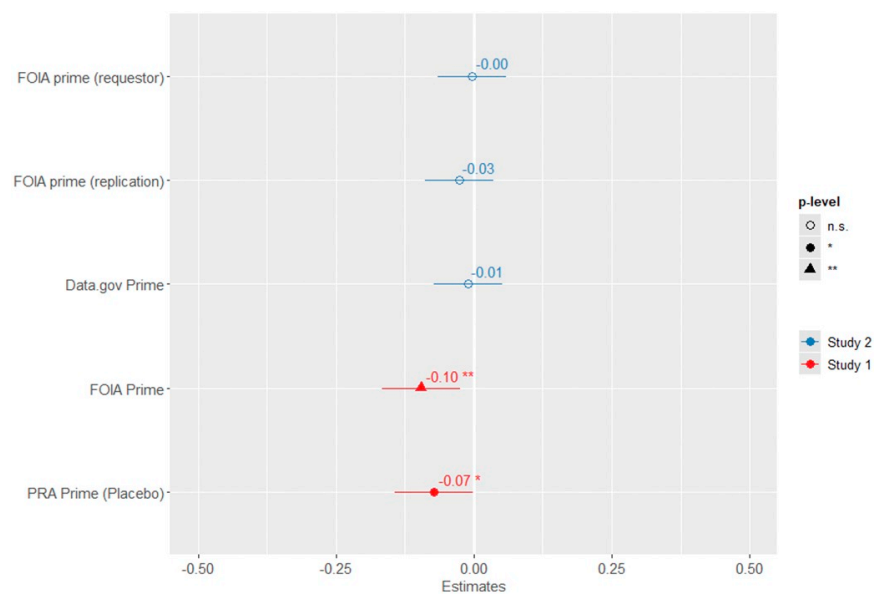

Fig. 3. Standardized regression estimates for trust in Study 1 and Study 2.

agenda would be to further test how latent transparency affects the public's view of trust under different circumstances, as opposed to the more common manipulations with manifest transparency.

We offer some possible interpretations of these unexpected findings. One is that although we aimed to activate positive values regarding transparency, our primes might have still had the opposite effect. Specifically, making people aware of FOIA may have prompted people to think about some of the unpleasant reasons for needing such a law to keep government agencies transparent in the first place (such as the problems of government secrecy and corruption). In other words, without the FOIA priming questions, participants may have had fewer active associations about these shortcomings or moral pitfalls of government. Similarly, the negative (although not statistically significant) effects of our placebo PRA prime in Study 1 may be from the reminder it provided of the high administrative burden (Moynihan, Herd, \& Harvey, 2015) frequently imposed by the paperwork requirements of many federal agencies. Hence, our FOIA prime may have activated attitudes not only about the virtues of transparency but also about the less noble reasons why such rules and requirements are needed as a check on government in the first place. That being said, even a more positively framed FOIA prime which focused on the requestor model, which we tried in Study 2, had no positive effect on trust in government.

An important consideration, however, is that our experiments, like others, only test the effects of transparency on immediate, short-term judgments and perceptions. As we found, priming people about FOIA does not lead to higher trust judgments of federal agencies immediately after the prime, in part, we suspect, because of having activated associations that have to do with the reasons for having a FOIA, such as reducing government secrecy and corruption. But it may be that latent transparency could have more positive, longer-term effects, to the extent it alters citizens' understanding of the political system. In other words, if people over time become more aware of latent transparency in the form of FOIA and the access it provides to government information, they may eventually develop more trust of government. Of course, testing this speculation would require a longitudinal study design in which latent transparency was promoted and trust levels were tracked over time.

Again, overall we found exposure to the latent transparency primes did not have the expected positive effect on trust in federal agencies. Indeed, there is some evidence from Study 1 that in specific circumstances there can even be a negative effect. For example, in Study 1, the negative effect of transparency awareness on trust was most pronounced in the case of the Department of Human Health and Services (HHS). We speculate that this may be because of the controversial issues surrounding HHS at the time of the study, namely the contentious health care debate in the United States. Indeed, we conducted Study 1 in October 2017 when the Trump presidency and debates about health care, along with issues like taxes, the justice system, and immigration, were causing deep divides in US political culture. According to a Gallup Poll in October 2017, the presidential approval rating remained under $40 \%$, and the Congressional approval rating hit a historic low of only $13 \%$. Given those conditions at that political moment, our FOIA prime in Study 1 may have simply reminded people about government shortcomings, particularly around contentious issues like health care, at a time when many people had especially negative associations with 
government. This interpretation is in part supported by the parallel effects of the PRA placebo prime, which was also negative (although not statistically significant in most of the models). Thus, the deep political polarization in the US, on top of a long decline in trust of government (Citrin \& Stoker, 2018), may have confounded our attempts to uncover a transparency-trust link.

Another related explanation is perhaps more fundamental and also more hopeful: The FOIA prime did indeed remind people of the value of transparency, but the nature of transparency remains rooted in a healthy skepticism of government-a skepticism that may account for the negative connotation of transparency in the mind of the public. This resonates with scholars arguing that transparency does not need to have positive consequences for trust because it is an intrinsic value of democratic government (Birkinshaw, 2006). In other words, thinking about transparency as a right leads citizens to think about the value of maintaining a skeptical attitude toward public agencies. Indeed, the very notion that transparency leads to trust, as the popular assumption of transparency and open government advocates holds, may represent a misunderstanding of the value and function of transparency in a democratic society. Just like freedom of speech and freedom of the press, transparency as a consciously held democratic value may well lead citizens to have a healthy skepticism and a more critical attitude toward government agencies and authorities. Perhaps this is what our experiments ultimately uncovered.

In conclusion, we offer a few suggestions for future research that might seek to build on our idea of latent transparency and its effects. To begin with, it might be worth trying other ways to prime latent transparency, including perhaps reading a more extensive description of FOIA or doing a writing or recall tasks, as has been effective in other experimental studies of trust of government (Faulkner, Martin, \& Peyton, 2015). Another option is to try different dependent variables that may be more proximate effects of latent transparency, such as perceptions of secrecy or corruption, as well as perceptions of procedural justice. In addition, future studies could test the latent transparency hypothesis in the context of local government, given that is closer to and generally more trusted by citizens. Finally, it would be helpful to examine latent transparency with other, non-experimental approaches such as survey research or qualitative methods to develop more insight and understanding.

\section{Author statement}

The authors contributed equally to the design, research, and writing of the paper and are listed alphabetically.

\section{Declaration of Competing Interest}

None.

\section{Acknowledgements}

This work was supported by the Pratt Program for Freedom of Information at Rutgers Law School; NWO [grant number VENI-451-15024]; an International Collaborative Research Grant from the Rutgers Global office; and the Center for Experimental and Behavioral Public Administration, School of Public Affairs and Administration, Rutgers University-Newark.

\section{Appendix A. Priming questions about the Paperwork Reduction Act}

The Paperwork Reduction Act (PRA) requires that agencies obtain Office of Management and Budget (OMB) approval before requesting most types of information from the public.

PRA is designed to reduce the paperwork burden the federal government imposes on private businesses and citizens.

- Have you ever heard about the Paperwork Reduction Act (PRA)?

- Did you know that federal agencies under PRA must provide a detailed explanation of how the information will be collected?

- Did you know that federal agencies under PRA must provide justification for why the collection of information is essential to their mission?

(Response categories were yes, maybe, no)

\section{Appendix B. Descriptive statistics}

Table B1

Descriptive statistics for trust by agency and treatment group, Study 1.

\begin{tabular}{lll}
\hline Agency & Treatment & Mean (SD) \\
\hline \multirow{2}{*}{ HHS } & Control & $62.3(23.5)$ \\
& Placebo (ARPA) & $56.8(25.1)$ \\
& FOIA & $51.8(25.2)$ \\
IRS & Total & $57.0(24.9)$ \\
& control & $53.3(27.0)$ \\
& ARPA & $48.7(26.5)$ \\
NASA & FOIA & $50.4(25.4)$ \\
& Total & $50.7(26.3)$ \\
& control & $69.3(21.7)$ \\
Total & ARPA & $69.3(23.5)$ \\
& FOIA & $65.3(23.3)$ \\
& Total & $67.8(22.9)$ \\
& control & $61.4(25.1)$ \\
& ARPA & $57.4(26.5)$ \\
& FOIA & $56.1(25.5)$ \\
& Total & $58.2(25.8)$ \\
\hline
\end{tabular}


Table B2

Descriptive statistics for trust by agency and treatment group, Study 2.

\begin{tabular}{|c|c|c|c|c|c|c|c|}
\hline Treatment & & IRS & HHS & NASA & DHS & DoEd & CDC \\
\hline \multirow[t]{2}{*}{ Control } & Mean & 54.0 & 62.4 & 70.6 & 58.8 & 54.8 & 68.9 \\
\hline & Std. Deviation & 29.9 & 25.8 & 25.3 & 28.0 & 29.2 & 25.4 \\
\hline \multirow[t]{2}{*}{ FOIA prime (replication) } & Mean & 53.3 & 61.0 & 67.3 & 60.7 & 57.9 & 65.6 \\
\hline & Std. Deviation & 27.9 & 26.0 & 27.2 & 27.3 & 26.9 & 27.6 \\
\hline \multirow[t]{2}{*}{ FOIA prime (requestor) } & Mean & 53.8 & 61.2 & 70.4 & 57.5 & 57.6 & 67.6 \\
\hline & Std. Deviation & 29.4 & 27.0 & 25.4 & 29.4 & 27.1 & 26.3 \\
\hline \multirow[t]{2}{*}{ Data.gov } & Mean & 52.2 & 60.3 & 68.3 & 58.3 & 56.3 & 67.7 \\
\hline & Std. Deviation & 29.3 & 26.0 & 26.9 & 28.0 & 27.8 & 25.9 \\
\hline \multirow[t]{2}{*}{ Total } & Mean & 53.3 & 61.2 & 69.2 & 58.8 & 56.6 & 67.4 \\
\hline & Std. Deviation & 29.2 & 26.2 & 26.2 & 28.2 & 27.8 & 26.3 \\
\hline
\end{tabular}

\section{Appendix C. Main effects of on perceived openness, Study 1}

\begin{tabular}{|c|c|c|c|}
\hline & Model 1 & Model 2 & Model 3 \\
\hline Treatment $(1=$ FOIA $)$ & -0.047 & -0.041 & -0.044 \\
\hline Placebo $(1=$ PRA $)$ & $-0.040+$ & -0.035 & -0.026 \\
\hline \multicolumn{4}{|l|}{ Control group (= reference) } \\
\hline Sex $(1=$ female $)$ & & -0.003 & 0.002 \\
\hline Age $(1=40$ or older $)$ & & 0.016 & 0.011 \\
\hline Party identification $(1=$ Dem $)$ & & $0.107 * *$ & $0.114^{* *}$ \\
\hline Education ( $1=4$ yrs. college or more) & & $0.107 * *$ & $0.113^{* *}$ \\
\hline Income ( $1=\$ 50 \mathrm{~K}$ or higher $)$ & & 0.015 & 0.026 \\
\hline \multirow{5}{*}{$\begin{array}{l}\text { Agency HHS } \\
\text { Agency IRS } \\
\text { Agency NASA (= reference) }\end{array}$} & & & $-0.126^{* *}$ \\
\hline & & & $-0.248^{* *}$ \\
\hline & $F=0.96$ & $\mathrm{~F}=4.05^{* *}$ & $\mathrm{~F}=8.95^{* *}$ \\
\hline & $\mathrm{R} 2=0.002$ & $\mathrm{R} 2=0.027$ & $\mathrm{R} 2=0.073$ \\
\hline & Adj. $R 2=0.000$ & Adj. $\mathrm{R} 2=0.020$ & Adj. $R 2=0.065$ \\
\hline
\end{tabular}

Standardized coefficients (Beta) shown in table. All VIF values $<1.380$.

$+p<.10 * p<.05 * * p<.01$.

\section{References}

Bannister, F., \& Connolly, R. (2011). Trust and transformational government: A proposed framework for research. Government Information Quarterly, 28(2), 137-147.

Bauhr, M., \& Grimes, M. (2014). Indignation or resignation: The implications of transparency for societal accountability. Governance, 27, 291-320. https://doi.org/10. 1111/gove.12033 doi:https://doi.org/10.1111/gove.12246.

Bertot, J. C., Jaeger, P. T., \& Grimes, J. M. (2010). Using ICTs to create a culture of transparency: E-government and social media as openness and anti-corruption tools for societies. Government Information Quarterly, 27(3), 264-271.

Birkinshaw, P. J. (2006). Freedom of information and openness. Fundamental human rights. Administrative Law Review, 58(1), 177-218.

Citrin, J., \& Stoker, L. (2018). Political trust in a cynical age. Annual Review of Political Science, 21, 49-70.

Coglianese, C. (2009). The transparency president? The Obama administration and open government. Governance, 22, 529-544. https://doi.org/10.1111/j.1468-0491.2009. 01451.x.

Cucciniello, M., Porumbescu, G. A., \& Grimmelikhuijsen, S. (2017). 25 years of transparency research: Evidence and future directions. Public Administration Review, 77, 32-44. https://doi.org/10.1111/puar.12685.

Cuillier, D. (2008). Access attitudes: A social learning approach to examining community engagement and support for press access to government records. Journalism and Mass Communication Quarterly, 85(3), 549-576. https://doi.org/10.1177/ 107769900808500305.

Cuillier, D., \& Piotrowski, S. J. (2009). Internet information-seeing and its relation to support for access to government records. Government Information Quarterly, 26(3), 441-449.

de Fine Licht, J. (2011). Do we really want to know? The potentially negative effect of transparency in decision making on perceived legitimacy. Scandinavian Political Studies, 34(3), 183-201.

de Fine Licht, J. (2014). Policy area as a potential moderator of transparency effects: An experiment. Public Administration Review, 74, 361-371. https://doi.org/10.1111/ puar.12194.

De Fine Licht, J., Naurin, D., Esaiasson, P., \& Gilljam, M. (2014). When does transparency generate legitimacy? Experimenting on a context-bound relationship. Governance, 24(1), 111-134.

de Fine Licht, J., Naurin, D., Esaiasson, P., \& Gilljam, M. (2014). When does transparency generate legitimacy? Experimenting on a context-bound relationship. Governance, 27,
111-134. https://doi.org/10.1111/gove.12021.

Faulkner, N., Martin, A., \& Peyton, K. (2015). Priming political trust: Evidence from an experiment. Australian Journal of Political Science, 50(1), 164-173.

Favero, N., \& Bullock, J. B. (2014). How (not) to solve the problem: An evaluation of scholarly responses to common source bias. Journal of Public Administration Research and Theory, 25(1), 285-308.

Gershtenson, J., \& Plane, D. L. (2007). Trust in government. American National Election Studies pilot report. Ann Arbor, MI: University of Michigan, Center for Political Studies.

Grimmelikhuijsen, S., \& Meijer, A. (2014). Effects of transparency on the perceived trustworthiness of a government organization: Evidence from an online experiment. Journal of Public Administration and Theory, 24(1), 137-157.

Grimmelikhuijsen, S. G., Weske, U., Bouwman, R. \& Tummers, L. (2017). Public sector transparency. In O. James, S. Jilke, \& G. Van Ryzin (Eds.). Experiments in public management research. Challenges and contributions (pp. 291-312). Cambridge, England: Cambridge University Press.

Grimmelikhuijsen, S., John, P., Meijer, A., \& Worthy, B. (2019). Do freedom of information laws increase transparency of government? A replication of a field experiment. Journal of Behavioral Public Administration, 2(1), https://doi.org/10.30636/ jbpa.12.34.

Hibbing, J. R., \& Theiss-Morse, E. (2002). Stealth democracy: Americans' beliefs about how government should work. Cambridge, England: Cambridge University Press.

Ingrams, A. (2018). Democratic transition and transparency reform: An fsQCA analysis of access to information laws in twenty-three countries. Government Information Quarterly, 35(3), 428-436.

Im, T., Cho, W., Porumbescu, G., \& Park, J. (2014). Internet, trust in government, and citizen compliance. Journal of Public Administration Research and Theory, 24(3), 741-763.

James, O., \& Van Ryzin, G. G. (2016). Motivated reasoning about public performance: An experimental study of how citizens judge the affordable care act. Journal of Public Administration Research and Theory, 27(1), 197-209.

James, O., Jilke, S., \& Van Ryzin, G. (2017). Experiments in public management research. Cambridge, England: Cambridge University Press.

Lourenço, R. P. (2015). An analysis of open government portals: A perspective of transparency for accountability. Government Information Quarterly, 32(3), 323-332.

Marvel, J. D. (2015). Unconscious bias in citizens' evaluations of public sector performance. Journal of Public Administration Research and Theory, 26(1), 143-158.

McDermott, P. (2010). Building open government. Government Information Quarterly, 27(4), 401-413. 
Meijer, A. (2015). Government transparency in historical perspective: From the ancient regime to open data in the Netherlands. International Journal of Public Administration, 38(3), 189-199.

Moynihan, D., Herd, P., \& Harvey, H. (2015). Administrative burden: Learning, psychological, and compliance costs in citizen-state interactions. Journal of Public Administration Research and Theory, 25(1), 43-69. https://doi.org/10.1093/jopart/ muu009.

Pasquier, M., \& Villeneuve, J. (2007). Organizational barriers to transparency: A typology and analysis of organizational behaviour tending to prevent or restrict access to in formation. International Review of Administrative Sciences, 73(1), 147-162.

Pew Research Center (2015). Beyond distrust: How Americans view their government. Retrieved from http://pewrsr.ch/1N7G6N8.

Piotrowski, S. J. (2016). The "open government reform" movement: The case of the open government partnership and U.S. transparency policies. The American Review of Public Administration, 47(2), 155-171.

Piotrowski, S. J., \& Van Ryzin, G. (2007). Citizen attitudes toward governmental transparency. The American Review of Public Administration, 37(3), 306-323.

Porumbescu, G., \& Grimmelikhuijsen, S. G. (2017). Linking decision-making procedures to decision acceptance and citizen voice: Evidence from two studies. The American Review of Public Administration. https://doi.org/10.1177/0275074017734642 vol (issue):pages.

Porumbescu, G., Lindeman, M. I., Ceka, E., \& Cucciniello, M. (2017). Can transparency Foster more understanding and compliant citizens? Public Administration Review, 77(6), 840-850.

Relly, J., \& Sabharwal, M. (2009). Government Information Quarterly, 26(1), 148-157.

Schnell, S. (2017). Cheap talk or incredible commitment? (Mis)calculating transparency and anti-corruption. Governance, 1-16. https://doi.org/10.1111/gove.12298 vol(iss).

Spáč, P., Voda, P., \& Zagrapan, J. (2018). Does the freedom of information law increase transparency at the local level? Evidence from a field experiment. Government
Information Quarterly, 3, 408-417. https://doi.org/10.1016/j.giq.2018.05.003.

Taber, C. S., \& Lodge, M. (2006). Motivated skepticism in the evaluation of political beliefs. American journal of political science, 50(3), 755-769.

Tolbert, C. J., \& Mossberger, K. (2006). The effects of E-government on trust and confidence in government. Public Administration Review, 66(3), 354-369.

Tyler, T. R. (2006). Why people obey the law (revised edition). Princeton University Press.

Tyler, T. R. (2013). Why people cooperate: The role of social motivations. Princeton University Press.

Van Ryzin, G. G. (2011). Outcomes, process, and trust of civil servants. Journal of Public Administration Research and Theory, 21(4), 745-760.

Worthy, B. (2010). More open but not more trusted? The effect of the freedom of information act 2000 on the United Kingdom central government. Governance, 23, 561-582. https://doi.org/10.1111/j.1468-0491.2010.01498.x.

Worthy, B., John, P., \& Vannoni, M. (2017). Transparency at the parish pump: A field experiment to measure the effectiveness of freedom of information requests in England. Journal of Public Administration Research and Theory, 27(3), 485-500.

Stephan Grimmelikhuijsen is an Associate Professor at the Utrecht University School of Governance. Core themes in his research are: government transparency, citizen trust in government and behavioral public administration.

Suzanne J. Piotrowski is an Associate Professor in the School of Public Affairs and Administration at Rutgers University-Newark. She is a member of the 2018-2020 U.S. Freedom of Information Act Advisory Committee.

Gregg Van Ryzin is a Professor in the School of Public Affairs and Administration a Rutgers University-Newark where he is also co-director of the Center for Experimental and Behavioral Public Administration (CEBPA). 